\title{
An Investigation into Tourists' Cognition of World Heritage Cultural Landscape - Mount Lu
}

\author{
Qing $X u^{1, a}$ \\ ${ }^{1}$ School of Art and Communication, China University of Geosciences, 430070, Wuhan, China \\ âingxu.cug@gmail.com
}

Keywords: Tourists, World Heritage Cultural landscape, Cognition

\begin{abstract}
World Heritage cultural landscape is not well known as a cultural heritage category to most of tourists in China though it has made great contribution to tourism. This paper focuses on tourists' cognition of World Heritage cultural landscape through a case study on Mount Lu. It explores tourists' view on what are the values of Mount Lu as World Heritage, what did tourists experience and what is significant for them. It is argued that the cultural value of Mount Lu is hard to be perceived and understood by tourists, and the social and economic values of Mount Lu as World Heritage property are also ambiguous for tourists. It suggests the need to draw attention to look closely at the level of tourists' understanding of the historical, religious and cultural value of Mount $\mathrm{Lu}$.
\end{abstract}

\section{Introduction}

'Cultural landscape' has become prominent in the field of World Heritage conservation and management since 1992 and been regarded as a frontier methodology of heritage conservation and development. It was adopted internationally by the World Heritage Committee with the intention of filling the gap between natural and cultural values in World Heritage sites. However, there is great difference of development of World Heritage cultural landscapes in various regions of the world, especially in Asia-Pacific area, which has different cultural context and view of nature [1]. There are totally 85 World Heritage cultural landscapes of the world and only 16 in Asia by 2013. It's also the same situation in China. The concept encountered difficulties in both theory and practice in China. China joined the 'Convention Concerning the Protection of the World Cultural and Natural Heritage' in 1985, but had never self-nominated a cultural landscape heritage until West Lake was nominated and inscribed as World Heritage cultural landscapes on the World Heritage List in 2011. Although China has made great progress in nominating World Heritage cultural landscape in the past two years, it has only 4 cultural landscapes inscribed on the World Heritage List by the end of 2013 and few researches so far. There are still a lot of confusion and doubt about the term for Chinese people. Since the outstanding universal value (OUV) as World Heritage cultural landscapes has not been clearly recognized and confirmed by local, the management objective of OUV is vague and thus greatly affects the sustainable conservation and management of them. As the scarcity and unique, many tourist destinations in China locate or relate with World Heritage sites. World Heritage sites are important places for visitors perceiving, sharing and disseminating heritage values. Awareness of OUV of World Heritage cultural landscape would affect visitors' experience at these heritage sites. To clarify tourists' perception and cognition of cultural landscape values is basic and necessary for Chinese World Heritage cultural landscapes conservation and management in both theory and practice.

The World Heritage cultural landscape definition and the three categories, as well as OUV have embraced the expanded concepts of landscape coming from cultural geography and other disciplines. They have underlined that cultural heritage is living history with rich connotation of the heritage, intangible value, rural heritage, and community participation. The World Heritage cultural landscape inscription requirements emphasize that it is important to include the full range of values represented in the landscape [2]. World Heritage Committee promotes different regions to explore how to 
interpret the OUV value of cultural landscape according to regional and local beliefs by including all relevant social groups to participate in heritage conservation and management. There have been several attempts to define and explain heritage tourism in the literature [3]. Yaniv Poria [4] suggests that tourists' perception of the site as part of their own heritage lies at the core of heritage tourism rather than the displayed heritage per se. investigating reasons or motivations for travel contributes to an understanding of tourism as a social and psychological phenomenon [5], and offers practical managerial insights [6]. Tourists' motives or reasons behind heritage tourism have been studied both theoretically and empirically. However, the empirical research is lacking on the link between the individual and the site, as well as on understanding attitude of tourists' toward World Heritage site.

Mount Lu's inscribed on the World Heritage List as a cultural landscape in 1996. The inscription has brought it a high reputation and made a great contribution to its tourism income. Two overarching goals guided this research: the first is to contribute to a holistic understanding of tourists' perception and cognition of Mount Lu's values as a World Heritage property, and second, to promote tourists' interaction with culture and nature of the World Heritage site. Although values of this area are embedded in different social groups, the objective of this paper is to conduct a brief survey on tourists' views and the actual perception in contemporary social context. It also gives some results and referable new data relating to subsequent work of the value recognition consensus and conflicts between stakeholders.

\section{Materials and Methods}

The Study Area. The whole study area is located in Jiujiang City, Jiangxi Province. Mount Lu occupies a total area of 30,200 hectares and its highest peak, Hanyang Peak, is 1.474 meters above sea level. Bordered on the north by the Yangtze River and on the south by Puyang Lake (Fig.1) . It presents an integral scene of river, hills and lake, the beauty of which has attracted spiritual leaders, scholars, artists and writers for over 2,000 years. Buddhist Temple begun in 386CE, Taoist Pagoda begun around 730 CE, Confucian Academy established in 940 CE, 600 villas built by Chinese and foreign visitors in the late $19^{\text {th }}$ are perfectly integrated with the natural beauty of Mount Lu [7]. Mount Lu has an important place in Chinese history and culture with high tourism value, known as one of Chinese four major summer resorts. It was inscribed on the World Heritage List under the cultural criteria in 1996, and also a Geopark.

Methods. Questionnaire surveys and interviews were mainly adopted to investigate tourists' perception, preference, and perspectives of Mount

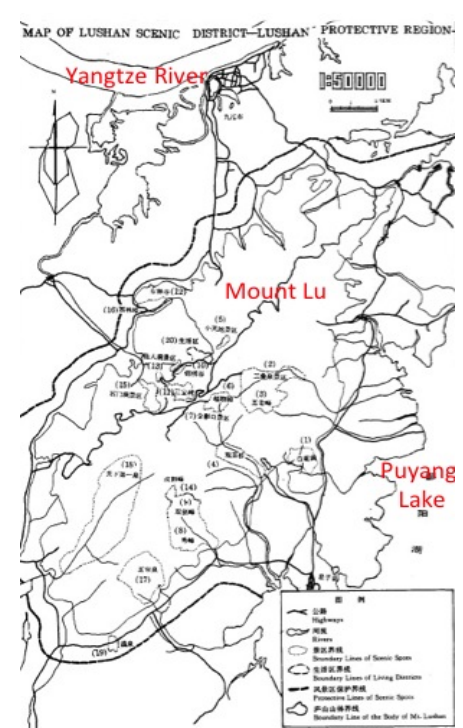

Fig. 1 Map of Mount Lu Lu as a World Heritage Cultural Landscape. The study proposed three key questions to organize the tourists' questionnaire design and investigation:

1) What is tourists' perception of Mount Lu as a World Heritage?

2) What are tourists' expectations of benefits from Mount Lu as a World Heritage?

3) What is tourists' attitude to other relevant social groups?

The preliminary questionnaire survey was conduced in November 2010 and the second questionnaire survey was taken in March 2011. We used the questionnaire data as sources of analysis. Analytic generalization was applied for data analysis instead of statistical generalization [8]. The quantitative questionnaires data were processed and aided by SPSS software. Most outcomes are presented in graphs and multiple choice question outcomes are presented in tables. 


\section{Results}

Basic Information. 125 tourists were involved in the questionnaire surveys. We got 51 cases and 70 cases from two surveys after sorting out the invalid cases, in total of 121 valid cases.

Male visitors (62.5\%) are more than female (37.5\%). $70.1 \%$ of the respondents were young people (aged 18-44, according to UN age group standards), few age of 18 minors and 60 years or older. $90.9 \%$ of respondents are visitors form other provinces of China and only $0.8 \%$ are foreign tourists (Fig. 2). 79.3\% of tourists have no religious beliefs and most of who have beliefs are Buddhists. More than half of respondents' education backgrounds were undergraduate, and none of junior high school or below. This shows that the overall cognitive ability of tourists are good. $86.7 \%$ of tourists visited Mount Lu for the first time, only 1.7\% of tourists visited more than once (Fig. 3). $66.4 \%$ of tourists stayed for 2-3 days in Mount Lu, 23.5\% of tourists took 1-day tour, and few long-term holidaymakers. This proves that the number of tourists is closely fluctuated with seasons. Generally, Mount Lu attracts a large crowd in the summer holiday and short-term excursions in other seasons. There are various reasons for tourists visiting Mount $\mathrm{Lu}$. 65.3\% of respondents were for watching the beautiful natural scenery, $29.8 \%$ of tourists for recreation and $15.7 \%$ for the culture of Mount Lu. It shows that the major attraction for tourists is the natural beauty of Mount Lu. This is consistent with that beautiful nature of Mount Lu is the most impressive character for $80.7 \%$ of visitors. Distinctive Chinese culture of Shanshui embedded in Mount Lu's hills and water impressed $43.7 \%$ of visitors and featuring historic buildings impressed $38.7 \%$ of visitors.

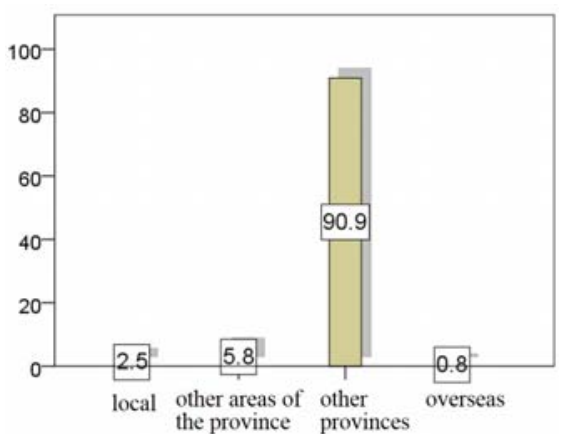

Fig. 2 Percentage of tourists source

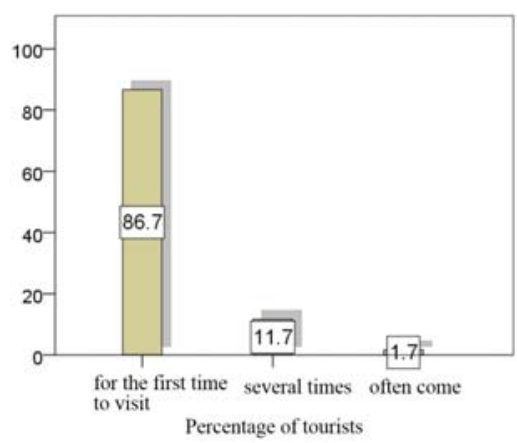

Fig. 3 The frequency of tourists to Mount Lu

Perspectives of Mount Lu as the World Heritage. Only 14\% of tourists knew Mount Lu is a cultural landscape heritage. Most of tourists (61.7\%) admitted that there is few ways of getting to know the category of Mount Lu as a World Heritage and they just judged it based on their knowledge. Though $25 \%$ of respondents learned it from the local tourism sector, however, only four visitors knew the right category of Mount Lu. 63.6\% of tourists agree that the World Heritage value of Mount Lu is the integration of natural and cultural landscape values. $27.3 \%$ of tourists thought that Mount Lu is a natural landscape and few regarded it as a cultural landscape. Although tourists admitted the cultural value of Mount $\mathrm{Lu}$, but $40 \%$ of respondents considered natural value is its most outstanding value. It suggests that cultural tours in Mount Lu is underdevelopment and fails to fully demonstrate the cultural value of Mount Lu.

Expected Benefits from World Heritage. From the perspective of self-interests, $81.8 \%$ of tourists considered that it should protect the natural environment of Mount Lu first, followed by $18.2 \%$ of tourists who favored promoting the development of tourism economy, and very few tourists pay attention to improve local people's living standards and the conservation of characteristics of history, culture and religion of Mount Lu.

The survey shows that most satisfying experience tourists got came from the natural environment of Mount Lu (71.6\%), which is followed by the historic and cultural experience. $70.1 \%$ of tourists thought that clouds, waterfalls and peaks and ridges of Mount Lu were most attractive sights and scenery. This is in stark contrasted with that only $4.5 \%$ of tourists were attracted by Temples and Academy. Few tourists were satisfied with the introduction about World Heritage and the local 
customs and traditions. $11.9 \%$ of tourists thought that the goal of visit was for meeting their aspiration to Mount Lu (Table 1).

Table 1 The most satisfying aspect of the visit

\begin{tabular}{|l|l|r|r|r|}
\hline \multicolumn{2}{|c|}{} & \multicolumn{2}{|c|}{ Respondents } & \multicolumn{1}{l|}{$\begin{array}{l}\text { Cases } \\
\text { Percentage }\end{array}$} \\
\cline { 3 - 4 } \multicolumn{2}{|c|}{} & $\mathrm{N}$ & \multicolumn{1}{c|}{ Percentage } & \\
\hline $\begin{array}{l}\text { Most } \\
\text { satisfyi } \\
\text { ng }\end{array}$ & $\begin{array}{l}\text { Beautiful } \\
\text { nature }\end{array}$ & 48 & $57.8 \%$ & $71.6 \%$ \\
$\begin{array}{l}\text { aspect } \\
\text { of the } \\
\text { visit } \\
\text { culture and }\end{array}$ & $\begin{array}{l}\text { Local customs } \\
\text { and traditions } \\
\text { Knowledge of } \\
\text { heritage } \\
\text { Others }\end{array}$ & 7 & $20.5 \%$ & $25.4 \%$ \\
In total & 8 & $3.6 \%$ & $4.5 \%$ \\
\hline
\end{tabular}

It illustrates that the natural beauty of Mount Lu is very impressive, while tourists could not interpret cultural landscape meanings and values of Mount Lu as a World Heritage. Visitors preferred natural landscape, which can be directly perceived than relatively abstract cultural landscape.

$52.9 \%$ of visitors' average daily spending was between 1 and 500 RMB, 35.3\% was between 501 and 1,000 RMB and very few visitors spend more than 1,000 RMB in a day. Although more than half of visitors agreed that the overall price of Mount Lu's tourism product was not high, but there was few middle or high consumers there. To some extent, it explains that tours in Mount Lu lack of attractive and visitors do not want to spend more.

Attitude to Other Relevant Social Groups. 52.1\% of respondents tended to exchange information of Mount $\mathrm{Lu}$ as a World Heritage with tourism practitioners. The proportion of tourist who exchanged information with government managers was equal to local residents, both accounted for $23.1 \%$. Tourists seldom chatted with the local religious people, other visitors or social groups.

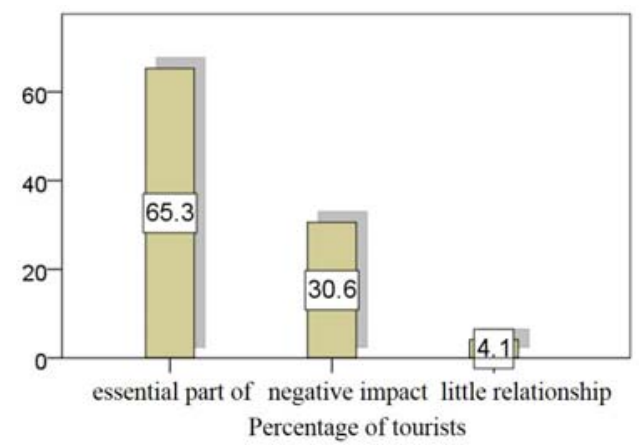

Fig. 4 Tourists' views on the relationship between locals' life and protection of World Heritage Because tourists contacted with tourism practitioners closer than other social groups, so tourism practitioners' understanding of Mount Lu as a World Heritage directly influence tourists' interpretation of Mount Lu's value.

$41.8 \%$ of visitors had good impression on local residents, and $34.3 \%$ on tourism practitioners. Tourists evaluated the administrator group mainly by its work such as the tickets mechanism, deployment of tours and tourism facilities. Regrettably, only $16.4 \%$ of visitors were satisfied with the management of Mount Lu World Heritage. Visitors believed that it is necessary to improve the management ability, construct better tourism facilities and increase cultural commentary to tourists. It is worth noting that $68.1 \%$ of tourists agreed that the religion culture is an important part of Mount Lu World Heritage, however, almost no tourists had impression on religious people, indicating that they didn't care about or interest in religion culture of Mount Lu. Although more than two-third of visitors (65.3\%) considered that the local residents' daily life is a part of cultural landscape of Mount Lu and needed to be protected, but there is still nearly one-third of visitors (30.6\%) thought local residents have a negative impact to the conservation of Mount Lu (Fig. 4). It's interesting that $79 \%$ of tourists considered that it is necessary to regulate local residents' number, which was contradicted with the previous finding that local people left a good impression to tourists. This result shows that tourists' tend to support regulating local residents from the point of view of their own interest.

In addition, more than half of visitors (55.2\%) agreed that business activities associated with religious could promote religious cultural tourism, but $31 \%$ of visitors considered that commercial activities would affect the solemnity of religion. The survey shows that it's better to guide and regulate such business activities than let them develop without any control. 


\section{Conclusion}

With the above results and analysis, we can see that most tourists to Mount Lu knew about World Heritage and the inscription of Mount Lu on the World Heritage List. Even though few of them know the exact heritage category, tourists recognize that Mount Lu's cultural landscape includes culture and nature, and the ecological value play a major role in Mount Lu' cultural landscape value. However, natural beauty is tourists' favorite experience along with the most prominent corresponding of tourists was on the protection of natural environment. The investigation illustrates tourists' confusion that they came to visit for the great reputation of Mount Lu's culture, but got great experience of its' natural beauty. Tourists highlighted natural value protection while thought cultural value is the most prominent of Mount Lu. It indicates the cultural value of Mount Lu is not been fully understood by tourist, or tourists' experience of Mount Lu did not significantly increase their perception of Mount Lu's culture. Furthermore, we can see the conflict in some tourists' view on the heritage protection of Mount Lu. Tourists have a hesitant attitude to local residents because they are hard to benefit from it. The social and economic values of Mount Lu as World Heritage property for tourists are also ambiguous. We can speculate that visit time, routes and interpretation around historical and cultural attractions in Mount Lu led to the status. There is a need to explore further what is the level of their understanding of the history, religion and culture of Mount Lu. These are not covered in our former questionnaire surveys and should be the focus of the next study. Notwithstanding its limitation, this study does lay a solid foundation for further study.

\section{References}

[1] Taylor, K., in: Cultural Landscape and Asian Values: Negotiating a Transition from an International Experience to an Asian Regional Framework, Chinese Landscape, Vol. 23(11) (2007), pp. 4-9

[2] UNESCO: Operation Guidelines for the Implementation of the World Heritage Convention edited by UNESCO World Heritage Centre, Paris (2011). Information on http://whc.unesco.org/en/guidelines

[3] Apostolakis, A., in: The Convergence Process in Heritage Tourism, Annals of Tourism Research, Vol. 30 (4) (2003), pp.795-812

[4] Poria, Y., R. Butler, and D. Airey, in: The Core of Heritage Tourism: Distinguishing Heritage Tourists from Tourists in Heritage Places, Annals of Tourism Research, Vol. 30 (1) (2003a), pp. 238-54

— in: The Meaning of Heritage Sites for Tourists: The Case of Massada, Tourism Analysis, Vol. 9 (1/2) (2003b), pp.15-22

- in: Links between Tourists, Heritage, and Reasons for Visiting Heritage Sites, Journal of Travel Research, Vol. 43(2004), pp.19-28

[5] Cohen, E., in: Who Is a Tourist? A Conceptual Clarification, Sociological Review, Vol. 22 (4) (1974), pp. 527-55

[6] Wight, P. A., in: North American Ecotourism Markets: Motivations, Preferences, and Destinations, Journal of Travel Research, Vol. 35 (1) (1996), pp. 3-10

Young, M. (1999). “The Relationship between Tourist Motivations and the Interpretation of Place Meaning.” Tourism Geographies, 1 (4): 387

[7] Information on http://whc.unesco.org/en/list/778

[8] Feng Han., in: The Chinese view of nature: tourism in China's scenic and historic interest areas, PhD submitted in part-fulfillment of the requirements for the Degree of Doctor of Philosophy, School of Design, Queensland University of Technology, Brisbane (2006), pp. 99 